Systems Practice, Vol. 5, No. 3, 1992

\title{
Tracking the Development of the Emery-Trist Systems Paradigm (ETSP) ${ }^{1}$
}

\author{
Oǵuz N. Babüroǵlu²
}

Received August 20, 1990; revised July 15, 1991

This paper is written to accomplish two objectives: first, to introduce the EmeryTrist systems paradigm to the critical systems thinking, a largely neglected and underutilized paradigm; second using a critical systems thinking framework, to provide a rational justification in an attempt to track the developments in the ETSP so that an extended heuristic map is offered to the scholars interested in the Emery-Trist systems paradigm. Four tracks within ETSP are identified and analyzed to produce a liberation theme that has not previously been articulated. The liberation theme imminent in all four tracks of the paradigm development denotes the value and the promise of the ETSP to the critical systems thinking community as well as to other systems thinkers.

KEY WORDS: Emery-Trist systems paradigm; sociotechnical systems; liberation; surrender; critical systems thinking; critical heuristics of social planning; democratization.

\section{INTRODUCTION}

The Emery-Trist systems paradigm (ETSP) has addressed redesign of workplaces, organizations, communities, and ecology of organizations within a participative and pluralistic democracy framework since the early 1950s. Yet a review of the accumulated body of literature on critical systems theory fails to reveal any meaningful reference to or use of the Emery-Trist systems paradigm beyond the pioneering coal mining study by Trist and Bamforth (1951) that was published in Human Relations. Based on this study, Jackson and Keys (1984) proceed to classify "the whole area of work known as socio-technical systems thinking" as "another attempt to come to terms with problems in systemicunitary contexts." As such, they claim that an assumed unitary goal (the primary

\footnotetext{
${ }^{1}$ An earlier version of this paper was presented at the 34th meeting of the International Society for Systems Science, Portland, Oregon, in July 1990.

${ }^{2}$ Management Department, Bilkent University, Bilkent, Ankara 06533, Turkey.
} 
task of a system) exists, which is best achieved through the joint optimization of the technical and social systems (a rebuttal to Jackson and Keys is given in Section 7).

Jackson (1988), in another paper, is consistent with his earlier categorization. He suggests that sociotechnical systems thinking shares the same orientation with cybernetics in recognizing the existence of true feedback loops in the systems studied where goal-seeking behavior is possible through management control and corrective action. Finally, Ulrich (1988) cites Emery and Trist's (1965) seminal paper on the causal textures of organizational environments as an example of a strategic management system which embodies resilience and innovative adaptation in the face of turbulent environments. It is a particularly difficult task to explain the discontinuity of references post 1965 among the scholars in the critical systems thinking school. The fact that both Eric Trist and Fred Emery are both alive and productive accentuates this difficulty. Additionally, Trist was one of the cofounders of the social systems sciences program at the University of Pennsylvania's Wharton School with Russell Ackoff, whose works are frequently quoted by the critical systems thinkers. Has the ETSP lost its appeal to critical systems theorists, or is it awaiting emancipation so that it can be integrated into the current debate on liberating systems theory? This premise coincides with Foucault's (1980) concept of the genealogy of knowledge and Flood's (1990) call to critical systems theorists to uncover suppressed knowledge so that the neglected discourse gets recognized in the process of the descent of systems thinking.

In this paper I review the developments in the ETSP and underline the relevance of this paradigm in critical systems thinking, while also exposing some misconceptions about it. This is done by using the questions raised by critical systems thinkers to liberate systems thinking, thus enhancing the ETSP within critical systems thinking. Further, this paper explicates the "contexts of application and justification" (Ulrich, 1987) by discussing the normative content of the ETSP. This leads to the analysis of the problem of practical reason to show the rational justification of the ETSP. This is accomplished by applying the critical heuristics of social systems design (Ulrich, 1983) to the different tracks within the ETSP.

Critical heuristics helps "to lay open, and reflect on, the normative implications of systems designs, problem definitions, or evaluations of social programs" (Ulrich, 1983). Critical heuristics based on the purposeful systems paradigm (Ackoff and Emery, 1972) and therefore the assessment of purposefulness, in terms of the inquiring, action, and valuation systems of the design, is an important starting point.

Ulrich (1983) developed a systematic list of questions and judgments to identify and to examine the "anatomy of purposefulness," which I apply to the different developmental tracks of the ETSP. Furthermore, Ulrich's (1983) com- 
plementary "quasi-transcendental" ideas, originally based on Kant's three "transcendental" ideas for systems rationality, are introduced.

Ulrich (1983) maintains that the original transcendental ideas-the cosmological, psychological, and theological-are critical standards for reflection. He interprets them to represent the systems, the moral, and the guarantor ideas. In any social system design, these three quasi-transcendental ideas are critical standards (1) to evaluate the extent to which the ideal of comprehensiveness is addressed in our maps of reality-this is the systems idea; (2) to assess the planner's interest in designing for a better social reality-this is the moral idea; and (3) to see what provisions have been made for securing the implementation of designs that are expected to improve the human condition-this is the guarantor idea. For each track of the ETSP, I attempt to uncover how the ETSP incorporates the systems, the moral, and the guarantor ideas.

\section{THE EMERY-TRIST SYSTEMS PARADIGM: AN OVERVIEW}

It is extremely difficult to do justice to the scope and the depth of what I call the Emery-Trist systems paradigm, since it would be attempting to extract the essence out of well over 100 publications for each of the partners, as well as a large body of literature generated by their colleagues, students, and critics. Yet I am unaware of any other literature that refers to their work using the "Emery-Trist systems paradigm" title (by paradigm, I mean an overall framework that includes the underlying philosophy, epistemology, ontology, methodology, ethics, theory, and practice adopted by Emery and Trist). However, studies relating to their paradigm have been referred to as sociotechnical systems, social ecology, organizational ecology, quality of working life, industrial democracy, participative democracy, new organization, action research, action learning, and open systems.

In introducing the ETSP to the current debate, this study deals with the ontological, epistemelogical, and methodological issues to the extent that Ulrich's (1983) dimensions of critical heuristics account for them. For instance, the epistemelogical issues pertinent to a particular ETSP track are discussed as a part of the assessment of purposefulness, and the ontological issues are highlighted in discussing the moral idea inherent in each track.

Because it is impossible to touch upon all facets of the ETSP, I rely upon four publications where this paradigm is reviewed and summarized in different yet convergent ways. Two of these publications were published in the early 1980s; one is by Trist and the other by Emery. The other two, published in the late 1980 s, are by two separate parties who have been close colleagues of either Trist or Emery. These parties are Wrigth and Morley, who both have worked with Trist at York University in Toronto and Hans van Beinum, Emery's long- 
time colleague. Trist's (1981) article divides the conceptual framework into the primary work system, the whole organization systems, and the macrosocial system levels. Emery (1982) calls for a new perspective by supplementing the new organization paradigm with an educational paradigm. Hans van Beinum (1990) traces the pillars of the paradigm, while Wright and Morley (1989) present a chronological and relational ordering of Trist's agenda. These frameworks are shown schematically in Fig. 1.

The four developmental tracks of paradigm development described below reflect my assessment of the field given these four review publications. It is important to note that the four tracks are not ordered in a linear sequence of development. The strands of all of the tracks of the paradigm are present in each track when viewed separately. The tracks should be considered as shifts within the same paradigm as opposed to shifts between paradigms as implied by Kuhn (1970). However, each of the paradigmatic tracks was developed extensively in response to different practical problems. All four tracks are grounded in the problem-solving and policy-making realities. The relevant problem-solving context is described at the beginning of each track so that the ETSP's emphasis on practice is adequately denoted.

\section{THE FIRST DEVELOPMENTAL TRACK OF THE PARADIGM}

For decades before the second world war, the prevailing mode of organization at the workplace developed in the direction of increasing bureaucratization. It was guided by Weber's description of increasing mechanization and by Taylor's principles of scientific management. According to Emery (1982), the adoption of these principles, resting on an objective division of labor and an assembly-line logic, moved industrialization to a second phase that he calls "machinofacture." This phase opposes the earlier "manufacture" phase stemming from the manual-facture, whose governing principle rested on a subjective division of labor.

The genesis of the first track of paradigm development starts with the recognition that productivity (in Britain) failed to keep up with the rate of mechanization. An investigation conducted by the Tavistock Institute of Human Relations into the coal mines revealed an innovative work organization in one of the seams. Trist (1981) describes this work organization as "consisting of a set of relatively autonomous groups interchanging roles and shifts and regulating their affairs with a minimum of supervision." The miners, in order to adapt to the new technological conditions, had adopted a work organization reminiscent of the unmechanized days (Trist et al., 1963). This combination of a new technological system with a social system, resembling that of the craft-cottage 




Fig. 1. The Emery-Trist systems paradigm frameworks.

work organization, resulted in high productivity, increased personal commitment, decreased absenteeism, and lowered the number of accidents.

This finding, reinforced by Trist's and Emery's sociopsychological background (also notice the first landmark identified by Hans van Beinum suggesting Lewinian roots), led to the development of what is known as the sociotechnical systems approach. This approach implies that the organization now has a choice (Emery and Thorsrud, 1976) for organizing work. One well-known principle of this approach is the consideration of a work system, often referred to as the primary work system, that can implement a set of activities in an identifiable and bounded subsystem of the whole organization (Trist, 1981). In the first developmental track of ETSP, the work group with discretionary work roles, as opposed to the individual job holder with prescribed work roles, becomes paramount. As such, the individual in the group is considered complementary to the machine rather than being an extension of it. As for the next pillar of the paradigm, Beinum (1990) points to the Norwegian industrial democracy project as testimony that participative forms of work organization did not endanger the technical or economic viability of the organizations involved in the project.

How does this development in the first track of the ETSP contribute to 
critical systems theory? In order to answer this question, Ulrich's (1983) critical heuristics framework for social planning is used to reconstruct the first track of the paradigm.

\subsection{Assessment of Purposefulness in Terms of the Inquiring, Action, and Valuation Problem-Solving Dimensions}

A sociotechnical system at the primary work system is an inquiring one because it possesses the kind of knowledge that continuously assists the work group with information regarding the nature of both the technical and the social systems optimizing the needs of both. The requirements of the social system are self-produced by the work system participants together with an action researcher. The requirements of the technical system are also generated by the work system under the most ideal circumstances. However, the emphasis is on the kind of knowledge generated to design the work system so that joint optimization of the social and technical systems occurs. Learning on the job and continuous learning become integral parts of joint optimization in sociotechnical systems.

The action concept in the sociotechnical system is self (work)-design with minimum critical specifications (this is why the work system is sometimes called semiautonomous), guided by internal regulation and choice regarding the scheduling, duration, task grouping, and rotation of work activities.

Democratic values centered around the freedom to affect one's own physical, technical, social, and psychological work environment directly are imminent within the sociotechnical design. Belonging to a group and participating in its functions and management are associated with improving the human condition. Some of the values associated with the job are variety and challenge, continuous learning, discretion and autonomy, recognition and support, meaningful social contribution, and designing desirable futures (Trist, 1983).

\subsection{The Anatomy of Purposefulness-Critically Heuristic Categories of Pragmatic Mapping}

\subsubsection{Motivation}

Emery (1989) identified the following path to demonstrate the source of commitment and motivation as follows: democratization of work leads to commitment, multiskilling, productivity, and quality. Therefore, democratization is viewed as the genesis of commitment and motivation. There is more room for individual preferences in democratized work groups than if they were in standardized work stations. 


\subsubsection{Control}

Once key variances are identified, the question "to what extent are the key variances controlled by the participants" (i.e., workers, supervisors, and managers) must be answered. Key variances affect either the quantity or the quality of production and either the operating or the social costs of production. The production goals and membership of self-managing groups become the subject of negotiation within the social system. In the new form of organizations, the preferred power relationship is symmetrical dependence between the workers, supervisors, and managers (Emery, 1982). Outside of the primary work system, some control can also be exercised over the "boundary tasks."

\subsubsection{Expertise}

Work roles are designed in such a way that there is variety and challenge, where continuous learning on the job is possible. Therefore, in terms of the operational aspects of the work system, the work group ought to have the necessary skills and knowledge of the necessary facts. The design effort itself is an action research process in which the social scientist as well as the client organization's interrelated work systems is involved. Therefore, an outsider can readily introduce his social science field practice to intervene in the process of design as an expert, analyst, consultant, or trainer. Later improvements involve the concept of a participative design workshop in which the role of the outsider consultant is reduced and design responsibility shifts to a group that represents a deep slice of the organization (Emery and Emery, 1978).

\subsubsection{Legitimation}

Beyond the effective functioning of the primary work system, the sociotechnical systems approach should incorporate the design of the entire organization, as well as the domain of the organization. This is assumed because of the "systemness" of the sociotechnical approach that primary work systems are embedded in the whole organization, which is itself embedded in an environmental domain. Despite an explicit tendency to continue involving "the affected" in the design process, the reported failures (Trist, 1981) often cite the lack of support from the "witnesses." Additionally, conflicting world views exist between the autonomous work groups and the observers who should have been codesigners. Legitimation is assumed to be one of the weaker aspects of the first track of paradigm development.

\subsection{Quasi-transcendental Ideas}

\subsubsection{The Systems Idea}

How can the ideal of comprehensiveness be pursued in the first track of the ETSP as if a completely intelligible whole system existed?

The work system consists of many relevant parts that contribute to its 
wholeness. The extrinsic and intrinsic properties of the jobs and the principles of design at the individual as well as the group level are exhaustively considered. The boundary relationship and the interdependence with neighboring systems are included in the pursuit of the ideal of comprehensiveness. The first track should, therefore, appropriately be characterized as liberation from the domination of the machine and mechanization. However, social, psychological, and organizational characteristics get much more attention in the sociotechnical systems design than the technical and intraorganizational political issues. There are, however, some notable success stories where the technology was designed around the work system, such as the Volvo plants at Kalmar and Uddavalla in Sweden.

The intraorganizational politics of the first track target the supervisor and the primary work system. To realize effective autonomous work groups, a radical redesign is conceived to address the intraorganizational politics. Redefinition of the role of the supervisor as a facilitator or a boundary spanner and the complete elimination of the role for a supervisor reflect some of the suggested redesign options. However, the politics between departments or within the organization at large are underconsidered in the first track.

\subsubsection{The Moral Idea}

How does the first track of the Emery-Trist paradigm help to improve the human condition?

The sociotechnical design emerges powerfully for improving the human condition at the workplace. No other systems approach to problem solving explicitly addresses itself to the workplace, to the inequities between technical and social influences in the workplace, and to the self-governing and -regulating ability of the workers. Not surprisingly, then, the first track of the ETSP is often referred to as the quality of work-life program that incorporates many sociotechnical interventions. Liberation from single and meaningless tasks and external control-inherent in the objective division of labor-mark the emancipatory orientation of the ETSP.

\subsubsection{The Guarantor}

How is the ideal for securing implementation of improvement conceived in the first track of the ETSP?

The built-in guarantor for the system lies in the system's ability to selfregulate and self-manage to the extent that the surrounding systems also selfregulate and self-manage or to the extent that the social system negotiates its ability to self-regulate. The self-governing quality of the work groups is the operationalization of the democratization value, which is key in securing the implementation of improvements. In organizations where there is more than one autonomous work group, a labor-management steering committee is enacted to serve the guarantor function within the organizational structure. 


\section{THE SECOND DEVELOPMENTAL TRACK OF THE PARADIGM}

The sixties ushered in a new phenomenon that Emery and Trist (1965) recognized in their paper on the causal texture of organizational environments. This phenomenon, described as a turbulent environment, implies that organizations have to cope not only with internal environmental factors, as in the first track, but also with contextual interdependencies sometimes arising independently from the organization itself. The organizations' adaptation hinges on their adaptive response capability when confronted with a rapidly changing context, increasing complexity, increasing interdependence, and the resulting uncertainty-specifically those characteristics that have come to be associated with turbulent environments. Therefore, the design emphasis in the second track shifts from the work system to the whole organization. The organization manages its internal and transactional interdependencies while being subjected to the contextual interdependencies that produce unpredictable demands and unexpected consequences of organizational actions.

Some principles of design emerged when the whole organization's adaptiveresponse capability was considered. The new principle of organization design was a redundancy of functions, as opposed to the redundancy of the parts of design principle of technocratic bureaucracies. The new principle helps in the creation of a more flexible and organic form of organization better suited to survive in turbulent environments. The new principle is also consistent and applies to the work system organization where the autonomous work groups embody the redundancy of functions within them. Consequently, new plants or organizations have fewer levels of management, fewer managerial personnel, and extensive sharing of power and information within a participative (not representative) democratic and self-regulative framework of decision making and problem solving.

Seen as continuous processes design and operations reduce the distinctions between the planners and the implementors to insignificant levels. The rapid change accompanying turbulent environments reaffirms the importance of continual learning, and finally, the essence of planning, called active adaptive planning, is the future's creation process. Therefore, the second track of the ETSP emphasizes liberation of the futures. Organizations, as well as the individuals within them, were considered ideal-seeking systems, with ideal-seeking seen as critical to the future's creation process since it embodies the values that steer the organization in the uncharted territories of turbulent environments.

The major landmark in this track was the development of a search conference methodology (Emery and Emery, 1978), which is the operationalization of the active adaptive planning. The search conference was designed as a faceto-face forum that would last about 2 to 5 days. The conference would enable 
a shared appreciation of changing contexts for comparison to the desired futures, while then leading the stakeholders to the design of strategies, action plans, and appropriate work organizations.

How does this development in the second track of the ETSP contribute to critical systems theory? Using Ulrich's (1983) framework for critical heuristics, I attempt to answer this question.

\subsection{Assessment of Purposefulness in Terms of Inquiring, Action, and Valuation Problem-Solving Dimensions}

In the second track of the paradigm Emery (1982) elaborates significantly on the processes of acquiring knowledge and the nature of learning. What Emery (1989) calls "direct perception" highlights the epistemological assumptions of the ETSP, explaining how (and by whom) meaningful knowledge is produced in order to move the whole organization toward its purpose. Emery (1982) sees the need for a shift from the new organizational paradigm to the new educational paradigm. According to Emery, from this new paradigm "knowledge emerges as the individual perceives the world" and "everyone is an expert to some degree from the moment their experience allows them some direct perception of the invariants in the environment with which they are interacting." As such, the second phase of the paradigm asks us to transform our notion of expertise and of human nature. This is because human nature possesses the ability to learn from experience and from each other and learn to learn from each other in the new educational paradigm.

The search conference is based on the assumption that critical commonsense perceptions and the inherited wisdom of the society (Crombie, 1984) are an appropriate starting point in the process of becoming a purposeful inquiring system and that all participants, as "barefoot social scientists" (Emery, 1982), can engage in a group process of reflection and evaluation of the knowledge they produce. In terms of the liberating systems theory, this marks liberation from the expert. This also denotes the orientation toward action. Liberation from the expert entails liberation from the planners, therefore, the implementors take charge of the design of their futures. The purposeful action system can then embody the properties of an ideal seeking system, and the energies of the organization can, as would be necessary in turbulent environments, be turned to collectively designing the most desirable futures.

Ideal seeking enables the organization to generate the values to guide any kind of strategic planning activity. In the face of unexpected and unpredictable consequences in turbulent environments, the normative orientation increases the adaptive response capability of the organizations. 


\subsection{The Anatomy of Purposefulness-Critically Heuristic Categories of Pragmatic Mapping}

\subsubsection{Motivation}

There is high sensitivity to the definition of who the client is and who the client ought to be. As Bain (1976) pointed out, the client presents a problem whose solution requires the identification of the client system. This can be clarified only after the "who the client ought to be" question is answered. Therefore, an ideal stakeholder map of all the entities who affect and who are affected has to be drawn. This is an iterative process where the mapping of the extended stakeholders' territory depends upon the client system. Subsequently, it is the client system that actually designs what the "client system" is in an iterative way. What belongs to the system and what does not is a judgment that is made incrementally, as the entire set of probable stakeholders is engaged in the process.

The new organization that the second track is meant to produce should align its purposes with those of the society and with those of the organization's members. As such, the approach in the second track is able to take the system, its environment, and the subsystems of which it is composed. Since the paradigm explicitly tries to incorporate the goals and worldviews of different groups of stakeholders, it is highly pluralistic. With these intentions, the second phase of the ETSP ought to facilitate the transformation of organizations so that they are better able to adapt to turbulent environments.

Regarding the search conference as a model organization that embodies the ETSP principles, the sources of motivation can be found within the searching process. Search conference methodology regards participation as voluntary, implying that a working group (of approximately 35 people) emerges out of the extended stakeholder territory. Parallel multisearch conferences are conducted when the number of participants exceeds $30-40$ people. The search conference methodology aims at creating a community that can design adaptive futures through a democratic process. One of the most significant measures of success in a search conference is how quickly the group becomes a planning and learning community able to reflect collectively on the past, present, and future of the whole organization and to control the search for adaptive strategies and forms of organizations.

\subsubsection{Control}

"All stakeholders are supposed to make their resources available without claiming special privileges of role and status" (Trist, 1981) to help with the transformation of the organization so that it can better survive in turbulent environments. Trist (1981) expresses the most remarkable feature of the second track as follows: "Sharing of power is a basic principle of the new model." Decision making is shifted from the individual to the group level. The basic 
unit of organization design becomes a self-regulating and self-governing group formed consistently with the redundancy of functions and redundancy of potentialities (involving the potential self-referential transformations of the system) (Ramirez, 1989) design principles.

One of the critiques of the second track in practice has been forwarded by Crombie (1984). He maintains that the basic issue in practice for starting democratic processes in traditional organizations requires the sanctioning of these processes by the top decision maker.

\subsubsection{Expertise}

As described above, the second track marks the liberation from experts and expertise. This is possible when the important distinction between environmental learning and abstract and skills learning is made. The kind of knowledge necessary for survival in turbulent environments is environmental learning. Here information can be taken directly from the environment without necessarily acquiring the abstract thought and practical routines whose results are stored as bodies of knowledge. Emery (1989) introduces the example of talking, which is knowledge acquired from the environment, and reading and writing, which are based on abstract symbols and social constructs. "In the new paradigm everybody is an expert" (Emery, 1982).

\subsubsection{Legitimation}

There is an explicit effort in trying to align the purposes of the whole organization with those of the society which consists of the witnesses. How does the ETSP publicly secure the consent of the affected through enacting law? The Norwegian trade union legislation exemplifies such an enactment that involves the trade unions extensively in decision making. The affected are given a chance to design the new organization in the search conference process. They participate as equal players in the search process, thereby not only helping with the liberation of the organization's future, but also emancipating themselves from the traditional way of viewing organizations.

\subsection{Quasi-transcendental Ideas}

\subsubsection{The Systems Idea}

How can the ideal of comprehensiveness be pursued in the second track of the ETSP as if a completely intelligible whole system existed?

I explained previously that the purposes of the members of the organization and the purposes of those who remain outside are equally important in determining the whole organization's purposes. The social system design in the second track of the paradigm development aims to align these purposes. This orientation is made explicit in the ETSP open systems assumptions and the way these assumptions are weaved into the design of search conference methodology. 
The systems idea is operationalized through the open systems concept adopted early on in the paradigm development process. Figure 2 shows the four components of the open systems concept-the system, the environment, exchange originating from the system into the environment, and exchange originating from the environment into the system. These are also labeled the internal interdependencies $\left(\mathrm{L}_{11}\right)$, transactional interdependencies $\left(\mathrm{L}_{12}\right.$ and $\left.\mathrm{L}_{21}\right)$, and external interdependencies $\left(\mathrm{L}_{22}\right)$. The search conference is designed to account for all four interdependencies and is regarded as a planning $L_{12}$ and a learning $L_{21}$ event since both of these transactional interdependencies are critical for self-regulation and self-government. Democratization and new forms of organization emerge from the way internal interdependencies are configured within a dynamic group process. Finally, the search starts from the environment $\left(\mathrm{L}_{22}\right)$, which is considered the source of learning and innovation.

\subsubsection{The Moral Idea}

How does the second track of the ETSP help improve the human condition?

Liberation from the expert, noninstrumental values to guide the normative planning process, futures creation and innovation, and experimentation replacing low risk-taking also aim at improving the human condition. The collective attempt to design desirable futures and the strategies to bring them about enables the members of the social system and those affected (stakeholders) to improve their condition in the present since they participate in the design process. In addition, the ability to design their own futures in the most desirable manner provides an opportunity to directly influence the human condition in the future.

\subsubsection{The Guarantor Idea}

How is the ideal for securing implementation of improvement conceived in the second track of the ETSP?

The guarantor in the ETSP is the self-reflecting, self-regulating, and selfgoverning capacities of the social system. The guarantor ensures the place and

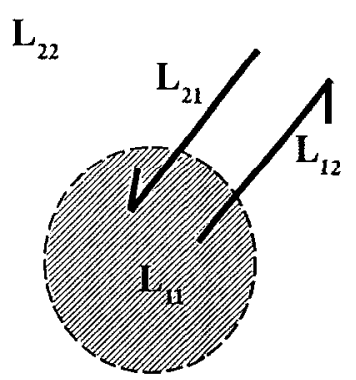

Fig. 2. The four components of the open systems concept: internal interdependencies $\left(L_{11}\right)$, transactional interdependencies $\left(L_{12}\right.$ and $\left.L_{21}\right)$, and external interdependencies $\left(L_{22}\right)$. 
value of democratization within the design process. Since the planned for and the planners' distinction is removed, the planned for, the affected, or the implementors themselves are engaged in the design and are, therefore, more likely to secure the implementation of their own designs than if the design were forced on them by some expert group.

\section{THE THIRD DEVELOPMENTAL TRACK OF THE PARADIGM}

The salience of turbulent environments and the concern about adaptation in turbulent environments lead to concentration on the interdependencies in the environment, $\mathrm{L}_{22}$. The third track was established with the publication of the jointly coauthored book entitled Towards a Social Ecology (Emery and Trist, 1973). In this book, social ecology directs the focus to the interdependencies between human institutions and human culture, both as figure and as ground (Vickers, 1973). The ecological emphasis-that of raising the unit of analysis from the single organization to the population of interdependent organizations and institutions-was further developed with the introduction of the "extended social field" (Emery, 1977) and the "organizational ecology" (Trist, 1977) concepts. Therefore, the third track marks liberation from the single social system referential design.

Societal problems, such as environmental degradation and economic revival, could no longer be dealt with solely by individual organizations. Instead, interorganizational domains (Trist, 1983), composed of members all concerned with the same set of problems, had to be activated, formed, and managed. This implied that there were some missing institutions which lie somewhere between the "micro and macro social scales" (Wright and Morley, 1989). Innovating organizations interconnecting organizational, industrial, societal, community, and personal development constituted what Trist (1978) called "the new directions of hope." The design principles for interorganizational domains reemphasized the ETSP essentials of participative democracy and participation, power sharing and complementarity, acknowledgment of multiple interest groups, and a negotiated order between them. The search conference methodology was especially suited for domain creation and planning.

The York University group coined a concept of action learning descriptive of what Emery called the new educational paradigm. This contrasts with action research, which expresses the engagement and intervention mode in the first track of the ETSP. Action learning "focused on the common transactional and contextual environments associated with the set of organizations drawn together around the domain issues" (Morley, 1989), as opposed to focusing on the internal environments of single organizations. Action learning facilitates a process whereby the participants go through a "subjective and a collective trans- 
formation of consciousness"' (Morley, 1989) regarding the existing boundaries of the systems in question. Furthermore, action learning aims at making it possible for learning to occur at the individual, group, organization, and interorganizational and societal (public) levels.

The LOM (leadership, organization, and codetermination) project currently under way in Sweden is one of the milestones for the third track of the paradigm development. Over 60 organizations are involved in finding and implementing innovative work systems, as well as sharing their findings with each other at an interorganizational level. As such, the nature of the intervention is multilevel, and the possibility of the diffusion of innovations increases significantly.

\subsection{Assessment of Purposefulness in Terms of Inquiring, Action, and Valuation Problem-Solving Dimensions}

In the third track, we find a similar assessment of purposefulness in terms of direct perception, ideal seeking, and a normative orientation to the planning and creation of futures as we did in the second track. Designing an inquiring system for a single organization is a necessary but insufficient condition to deal with the complex societal issues that the third track of paradigm development addresses. The interdependencies in a multiorganizational domain need to be collectively shaped in order to cope with societal problems. Similar to the second track, collaboration is the appropriate value base for the cultivation of interdependence. But unlike the second-track development, what Trist (1983) calls a "referent organization" emerges to provide leadership to the domain to tackle the meta-problems, without substituting any of the functions of the constituent organizations.

In the third track, two social system designs prevail. First, a search conference type process and structure form the interorganizational domain so that a shared appreciation of the meta-problem is possible. Also, the domain acquires an identity, agreed-upon directions and boundaries for the domain are set, and an internal structure for the domain coordination emerges. Second, a referent organization comes into existence to coordinate the present relationships and activities through the setting of some ground rules: the appreciation of emergent trends and issues is brought to the domain, as well as developing a shared image of the future (Trist, 1983). Trist (1983) also sees infrastructural support as one of the functions of referent organizations. When these designs are taken at a more conscious level, such social systems will become more purposeful.

In both search conference and referent organizations, people act as themselves, and not their organizational roles. Therefore, they can bring their own values and concerns more readily into the design process. Since individuals change faster than organizations, the values beneficial to shaping the future will 
come from individuals who can act themselves. This can be phrased as liberation from existing institutional and organizational constraints.

\subsection{The Anatomy of Purposefulness-Critically Heuristic Categories of Pragmatic Mapping}

\subsubsection{Motivation}

Motivation spawns from the self-regulating, self-governing, and self-initiating emphasis of the ETSP. However, the concept of "self" is transformed from that of a single organization to an interorganizational domain. Furthermore, it is an awareness that needs to be developed, since many organizations that are impacted by a serious meta-problem may not have considered collaborative strategies for resolving the meta-problem. This approach may also run against the existing political culture, particularly in countries where there is a strong interventionist central government. Trist's (1978) thesis claims that interorganizational domain is an alternative to overcentralization and chaos. Trist (1978) claims that hope must come from four directions-from outside, below, the middle, and across-for an interdependent domain to develop. By outside, he means the periphery, and not the center; by below, he means the bottom up, and not the top down; by the middle, he means the levels of society between the nation state and the single organization; and by across, he means the networks which are mediated by individuals who cross organizational boundaries.

\subsubsection{Control}

Although the organizations in a domain are closely connected, no single organization is in control, and all are expected to surrender some of their sovereignty to enable the emergent democratic order to provide some direction. The democratic order emerges through the mutual adjustment of all the stakeholders, namely, the constituent organizations. Trist (1983) states that there is little experience of democratically ordered domains, and the evolution of such self-regulating domains will remain as one of the major challenges.

The control function of the referent organization for the realized domain would be in terms of setting ground rules and maintaining the base values that surfaced in the domain formation and activation stage. It would monitor the developments in the meta-problem area and inform the constituent organizations about the current and emerging trends. The referent organization has to secure funding to undertake any action mandated by the constituent organizations. Usually, multiple sources of funding constitutent organizations and from public sources are desirable so that no single funding source obtains undesigned power over the referent organization. The referent organization itself can be structured with participative rather than representative democracy principles where the members of the domain take turns in serving, much like the United States jury system (Emery, 1989). 


\subsubsection{Expertise}

The referent organization should be able to develop some distinctive competence regarding the shared issues and shared futures of the interorganizational domain. It should be able to deliver, in a way visible to the stakeholders, what, so far, has or has not been accomplished. The referent organization itself should be capable of action learning and also of facilitating the continuous learning of the interorganizational domain. Although some staff may be necessary to run the referent organization, they should not be considered permanent, since the referent organization itself may be temporary due to the temporary nature of the meta-problem. The domain may approach the staff function as one to be fulfilled by constituent members in turn, as opposed to hiring permanent staff who might create their own bureaucracy.

\subsubsection{Legitimation}

Legitimation involves the voluntary consent of the affected in a socially rational planning process (Ulrich, 1983). The process of legitimation here matches the one in the second track of the paradigm. A more direct and explicit link exists between those who are affected, since the third track takes the societal meta-problems as a subject that requires a response. Hence, there must at least be some awareness of the nature of the societal problem in those who are affected. Yet it may not be a shared awareness. This is why a domain-wide search conference is aimed to produce a shared appreciation of the meta-problem by the stakeholders.

\subsection{Quasi-transcendental Ideas}

\subsubsection{The Systems Idea}

How can the ideal of comprehensiveness be pursued in the third track of the ETSP as if a completely intelligible whole system existed?

The third track of the paradigm development introduces a figure ground reversal. Whereas the organization was regarded as the figure and the environment as the ground in the previous track, in the third track the environment became the figure. Interorganizational domains were considered functional social systems, occupying a space between the whole society and that of a single organization. While sharing the same systems principles as in previous tracks, the social system design level is elevated to the interorganizational domain, where a more comprehensive and inclusive process of collective response can be planned by the stakeholders.

\subsubsection{The Moral Idea}

How does the third track of the ETSP help to improve the human condition?

The third track brings the social system - the interorganizational domainmuch closer to the problems plaguing society. If these problems are resolved, 
then the human condition will have a better chance of continuing improvement. Furthermore, the human condition stands to be improved because the interorganizational domain provides adaptive capacity, if not for the present, for crisis and contingent situations.

\subsubsection{The Guarantor Idea}

How is the ideal for securing implementation of improvement conceived in the third track of the ETSP?

The referent organization-which coordinates, provides a leadership function, and helps with the design of shared futures for the domain-acts as the guarantor that secures implementation. As discussed previously, it does not usurp the functions of the constituent organizations; rather it provides the kind of regulatory, leadership, and informational function that helps to maintain the identity, as well as the continuity, of projects which may have been triggered by the domain in a search conference-like process.

\section{THE FOURTH DEVELOPMENTAL TRACK OF THE PARADIGM}

This track began with the realization that active adaptive responses may fail to be enacted by social systems that are immersed in turbulent environments. Additionally, this track recognizes that conflict that was assumed to be manageable in the previous tracks of the ETSP may become unmanageable and destructive. There are diverse examples of such situations ranging from international conflicts, such as the north-south stalemate and the thawing cold war, to organizational (labor-management) strifes. There is a demand to revise continuously the current institutions and design new ones when confronted with turbulent environments, the effects of which are perpetual shifts, transitions, and changes in the extended social field. But some social systems will not be able to adapt to an apparently permanent state of transitions (Babüroǵlu, 1988) or to an unstable state (Schon, 1971) that exasperates adaptation responses further into what is called a hyperturbulent (McCann and Selsky, 1984) or a vortical (Babüroǵlu, 1988) environment.

Vortical environment has a different causal texture that emerges when maladaptive responses to turbulent environments persist seemingly indefinitely. The maladaptive responses to turbulent environments that rigidify all of the selfregulating, self-governing, self-managing, self-planning, and self-learning capabilities of social systems are represented by stalemate, polarization, and dogmatism-stalemate connoting "being stuck in the middle" of a transition, a denial at the system level of purposefulness that ruptures means-ends continuities. Polarization, often manifested by intense ingroup-outgroup dynamics, and 
the us-them syndrome at the level of the parts in systems terminology both describe how the parts are "charged" positively toward some and negatively toward others. Also, dogmatism is the type of cognitive response in which reality and the way of perceiving reality are absolute. The decision makers are locked into a closed, cognitive organization of their beliefs by regarding only one method of resolving system integration and differentiation problems as the absolute, true way.

These three maladaptive responses effectively seal off the system from the rapidly changing environment so that the transactional interdependencies wither away, the parts immobilize each other, and each of the parts advocates an unnegotiable and authoritative resolution of the system's problems. The new causal texture, labeled the vortical environment in the Emery-Trist levels of organizational environments, is thus produced by processes connoting rigidity and closure, as well as by processes connoting change and instability. The external interdependencies $\left(\mathrm{L}_{22}\right)$ continue to generate the changes and, hence, instabilities; however, the internal $\left(\mathrm{L}_{11}\right)$ and transactional interdependencies $\left(\mathrm{L}_{12}\right.$ and $\mathrm{L}_{21}$ ) rigidify and make the social system act like a closed system.

As such, the fourth track of the paradigm development, to be considered liberation from harmony and concensus approaches, begins an extensive theoretical effort to weave the conflictual and paradoxical realities of social systems into the ETSP that Trist (1985) refers to as the dark side of humanity. Such a conceptualization of vortical environments elevates the importance of new ways of thinking about the survival of social systems immersed in vortical environments.

The previous principles of adaptation in turbulent environments, such as participative democracy, value-driven institutionalization, and power sharing, are all warped in the fourth track. In a highly charged polarized social field, when all parties appear to want to eliminate each other, a mutual ground is very difficult to generate, let alone designing it in a participative manner. Power sharing is institutionalized as power equity in stalemated social systems in order to obstruct other parts from reaching their goals and, thus, imposing their truth on the whole system. However, new survival approaches would need to be consistent, in some sense, with the ETSP. This consistency is accomplished by utilizing the logical extension of the ETSP argument in the third track.

In the third track, the design focus was directed toward interorganizational domains, and the participating organizations were expected to surrender some sovereignty in exchange for active adaptation to turbulent environments. In the fourth track, therefore, survival depends on the existence of some realized or latent interorganizational domains that have woven the texture in advance, making it "firm" enough for a social system and providing a safety net in which to fall. Furthermore, the aforementioned social system, interested in preserving its integrity, should be able to hide in the interorganizational domain provided 
it is willing to surrender extensive sovereignty to the interorganizational domain. Otherwise the social system will move toward another logical end, that of total disintegration beyond recognition and continuity.

\subsection{Assessment of Purposefulness in Terms of Inquiring, Action, and Valuation Problem-Solving Dimensions}

In the fourth track, the object of inquiry and design is a social system that not only is subject to turbulent conditions, but also is persistently unsuccessful in terms of developing active adaptive strategies. The consequence of the active maladaptive strategies, such as stalemate, polarization, and dogmatism, is a social system that has exhausted its adaptive capacity by adopting the exact opposite of what is called for in turbulent environments. Instead of maintaining a flexible, open structure and cognitive orientation, the opposite has resulted: a rigidifying and closed structure and cognitive orientation. Rather than managing the transactional and internal interdependencies to adapt to a changing environment, attention turns inward, to the moves and countermoves that must be designed to obstruct the other parts from gaining an advantageous enough position to be able to define the social system's purposes.

Stalemated social systems are characterized by the inability to design an agreed-upon purpose or a mutually agreeable (to all stakeholders) image of the future for the social system as a whole. Action planning is directed exclusively to regulate the internal interdependencies, as opposed to the transactional ones, with the purpose of obstructing the other constituent parts from reaching their objectives. Inquiry rests on obtaining information about the opponent's actual or planned moves and interpreting the consequences of those moves. A value system is adopted-one that seeks to resolve all uncertainties and tensions of the past, present, and future, once and for all.

Since polarization governs the moves and countermoves construed to attack and defend, no neutral party can survive for any meaningful length of time. Therefore, in the stalemated organization or domain, no party within the same organization or domain has the legitimacy to intervene in order to resolve the protracted conflict. Therefore, the environment, or that which remains outside the stalemated situation, must provide adaptive capacity to the organization and act as the source of intervention.

First, to cope with a vortical environment, a social system design must utilize existing adaptive capacity in the environment, as constructed by the successful third ETSP developmental track initiatives. Actual or latent interorganizational domains, institutionalized to provide at least a temporary safe haven or/and to offer an integrated framework to an organization on the verge of disintegration, are expected to be the locus of intervention. Second, the stalemated organization or domain must be able to follow a surrender strategy, which 
can be accomplished only if the stalemate has reached, or has been brought (by the environment) to, a threshold point. Therefore, environmental capacity, a threshold point or event, and a surrender strategy are necessary elements of social system design in the fourth track (Babürogilu, 1991).

\subsection{The Anatomy of Purposefulness-Critically Heuristic Categories of Pragmatic Mapping}

\subsubsection{Motivation}

The source of motivation in the fourth track originates from the outside, as in the third track. As explained previously, the environment has sufficient adaptive capacity, as represented by existing interorganizational domains or latent networks. The interorganizational domain can be catalyzed in order to facilitate the reweaving function for an organization descending into a vortical environment. This domain is again composed of the stakeholders of the organization, and therefore, the purposes of the stakeholders are served in reintegrating the organization back into the environment. This is also consistent with a stalemated social system that vacillates between the purposes of its parts, unable to arrive at a purpose for the system as a whole. This statement should not be misinterpreted to mean the advocation of only one purpose for the social system as a whole, but as some mutually agreed upon purpose or purposegenerating process.

\subsubsection{Control}

Stalemate is a consequence of various interest groups trying to assert their will on the organization in order to control the situation to remain consistent with their objective and in order to derive other benefits. A pathology of mastery is evident in stalemated situations because nobody ends up winning and a resolution that satisfies all parties is not reached. When consciousness of "no win" or "lose-lose" begins to set in as a result of reaching the threshold point, the surrendering strategy is meaningful and liberation from trying to control enters the social systems agenda of action. The organization surrenders to the temporal network to freeze the day-to-day demands on it and to allow it to reflect on its past, present, and future. Through surrender, it is possible to come to terms with the whole organization, to reaffirm its original purpose, or to design a new one. Since the network facilitates the surrender and serves as a halfway house, the constituent stakeholders share in both the examination and the reconstructive effort. Surrender, therefore, is the experience of unity, of "systemness," and of belonging to a larger system which was lost in a vortical environment.

\subsubsection{Expertise}

The know-how for constructing interorganizational domains follows the same processes of development explicated in the third track of the paradigm development. Once the stalemated social system reaches the threshold point, 
the environment that provides reconstructive support would initially need to withdraw support in order to bring the stalemated situation to a threshold point. Surrendering requires an ability to suspend the preconceived notions pertaining to the courses of action, programs, and projects that have strapped the social system into a stalemated state. By suspending received notions of dogmatism, the organization tests its biography and the various transitions that have precipitated it. The only unsuspendable basis of surrender is the faith that surrender is possible and that suspending preconceived notions of dogmatism liberates the social system and commits the system further into a liberating faith.

\subsubsection{Legitimation}

Both the affected and the witnesses to the adaptation processes in vortical environments carry a special significance in the fourth track of the paradigm development. While in the previous developmental track they provided the moral support and reminded the stakeholders of their responsibility vis-à-vis the social system in question, they can no longer be thought separate from the social system's stakeholders. The witnesses must now enter into the formation of interorganization domains in anticipation of stalemated situations that might arise in emerging vortical environments. This implies that the entire population must seek ways to manage domains and networks that could play significant reconstructive roles for stalemated social systems.

\subsection{Quasi-transcendental Ideas}

\subsubsection{The Systems Idea}

How can the ideal of comprehensiveness be pursued in the fourth track as if a completely intelligible whole system existed?

The active surrendering strategy is the expression of seeking an intelligible whole system within the self (i.e., the social system) so that it can be reintegrated into the environment. The fragmentation that the social system experienced as a result of being locked into maladaptive responses now leads to unity. Surrender requires an ability "to let go" of the desire to try and assert individual desire on the social system to control and to master its destiny. Instead, the social system, by surrendering into an existing or latent interorganizational domain, opens up the possibility of relying on the requisite variety of the environment to find an intelligible and viable whole within itself.

\subsubsection{The Moral Idea}

How does the fourth track of the ETSP help to improve the human condition?

A society must accommodate the social systems that have entered into a pattern of apparently self-destructive action, and it must provide the slack resources for reconstructive work to be undertaken. The readiness for such 
accommodation in the form of actual or latent interorganizational domains is testimony for improving the human condition. The social system seeking such protection surrenders into this interorganizational domain-of which the social system might have been a partner of its creation-to search for ways of giving birth to a new conception of itself, a new way of being in the world, and a new beginning. Everything lying outside the field of preconceived notions and dogmatism begins to gain pertinence in the searching and questioning process. Hence, a new "self" more connected with the rest of humanity and better anchored in the social and organizational ecology emerges.

\subsubsection{The Guarantor Idea}

How is the ideal for securing implementation of improvement conceived in the fourth track of the ETSP?

For improvement to take place in a stalemated social system, it must come to an unfreezing (in Lewin's sense) point. This point is unpredictable in advance since the duration of stalemates differ depending on the nature of the social system. Hence, it cannot be willfully designed by the social system, its parts, or the environment. However, the general intervention approach, what may be called "paradoxical intervention," induces the arrival at a threshold point (by paradoxical intervention, I mean the implementation of counterintuitive, and often contrary to preconceived notions, strategies). As previously noted, stalemate holds the social system in the middle of a transition and polarization helps to sustain that state in "limbo." A paradoxical intervention may, for example, require the temporary institutionalization of the "limbo" status so that the social system, by not being able to go through the transition and owing to other factors, can attempt to become self-reflexive rather than self-assertive. The social system may then be able to consider a surrender strategy.

Securing implementation of improvement in the fourth track is therefore more than the existence of adaptive capacity in the form of actual or latent interorganizational domain. To secure the implementation of improvement requires stakeholders to approach a stalemated situation in unconventional and paradoxical ways.

\section{CONCLUSIONS}

A rebuttal to Jackson and Keys' (1984) classification of the "whole area of socio-technical systems thinking" as an approach embedded in a systemicunitary context can now be presented. As an initial critique, I do not deal with their reduction of the entire area, presumably all four tracks into one, since the above discussion of the four tracks indicates that the reduction oversimplifies the case. However, as a second critique, I address the classification of the sociotechnical systems into a unitary context, as opposed to a pluralistic one. 
According to Jackson and Keys (1984), a problem context is unitary if the decision makers are unitary, which implies that the decision makers agree on a common set of goals for the whole system. Conversely, the context is pluralist when the set of decision makers is pluralist, which implies that the decision makers cannot agree on a common set of goals for the whole system.

The second critique rests on Jackson and Keys' (1984) assumption that the primary task in the sociotechnical systems thinking is the unitary goal. The concept of "primary task" is used in the sociotechnical systems methodology to define the conversion process that the system must perform if it is to survive (Miller and Rice, 1967), and not to describe the predisposition of the decision makers of the social system. The primary task is a heuristic concept to sort out the critical processes that the system must carry out in order to exist from the activities taking place in a sociotechnical system (Cummings and Srivastva, 1977). The definition of the primary task-an important part of the methodology-is a collective act in which all stakeholders (for example, the unions, management, etc.) participate. Furthermore, the definition of the primary task frequently leads to conflict within the system or between the system and its environment. This indicates that a "solution" acceptable to some will not be acceptable to others, which is one of the conditions for a pluralistic context as laid out by Jackson and Keys (1984). In fact, methodologically, the definition of the primary task is akin to designing the "idealized futures" of Russell Ackoff (1974) and expressing the "root definitions" of systems relevant to the problem situation of Checkland's (1981) methodology. Since, Jackson and Keys (1984) classify both Ackoff's (1974) and Checkland's (1981) methodologies as adept in dealing with systemic-pluralistic problem contexts, they should have also classified the sociotechnical systems methodology within the same pluralistic category.

Jackson and Keys' (1984) misclassification brings forward an aspect of the methodologies better suited to address systemic-pluralistic contexts which have remained latent and have been made explicit only in the fourth track of the ETSP. This aspect in Ackoff's, Checkland's, and the first three tracks of the ETSP related methodologies is the underlying assumption that a participatively and pluralistically designed notion (call it idealized design, root definition, primary task, or desirable future) is possible. This is the belief that, however conflictual the stakeholders might be, there can eventually be a mutually agreed upon and desired notion to proceed from or to strive toward. Only in the fourth track of the ETSP is this belief suspended, since holding onto it would be a further testimony to the pathologies of control and mastery that produced the unrelenting conditions of vortical environments.

The fourth track of the ETSP embodies the belief that it is impossible for the stakeholders to define or to redesign the system for which they may be a decision maker. Therefore, those decision makers embedded in highly polarized 
and conflictual contexts must consider methodologies that include characteristics enabling the stakeholders to surrender control. Such a radical liberationist approach to designing methodologies which enable surrender is feasible only in the fourth track of the ETSP because of the emancipatory tradition of the ETSP.

The question that I raised earlier-Has the Emery-Trist systems paradigm (ETSP) lost its appeal to critical systems theorists, or is it awaiting its own emancipation so that it can be integrated into the current debate on liberating systems theory? - can now be answered. Based on the rational justification of each of the four tracks of the ETSP, it is clear that the ETSP should finally be addressed by the critical systems thinkers and that critical systems thinkers should join in the further emancipation of the ETSP and its integration into the current debate. I make this call because the ETSP shares the same fundamental commitments, such as the commitments to emancipation, critique, and pluralism, as stipulated for critical systems thinking by Schecter (1990). The ETSP has an emancipatory tradition embedded in its roots and has developed participatory methodologies that have been applied in hundreds of settings to bring about social change to reach its long standing meta-objective of democratization.

As shown in Fig. 3, the attempt to apply Ulrich's (1983) critical heuristics uncovered a very consistent liberation theme in each track of the ETSP. This liberation theme is the testimony to the emancipatory commitment of the ETSP. Such a liberation theme exposes how oppression in many aspects of social system design and management can be removed. It empowers the critical systems thinker with a liberating faith as opposed to a controlling faith. Liberation from the machine, from external control and experts, from the entrapments of the past and the present, from organizational and institutional constraints, from a perspective of appreciating only a harmonious reality, and finally, from self-

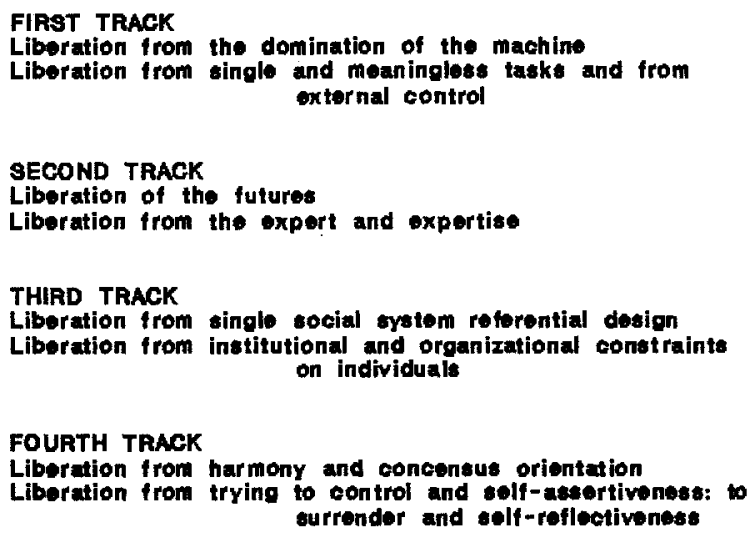

Fig. 3. Liberation theme. 
assertiveness and mastery are the components of the theme that justify the liberating faith.

The next significant theme to which the above justification of the ETSP alludes reveals the problem and practice emphasis. The paradigm development has been guided by pressing problem contexts grounded in the everyday realities of social systems in which action researchers have found themselves. In the first track, it was the development of the technical system that moved faster than the developments in the social system. In the second track, it was the realization that social systems had to cope with turbulent environments produced by the increasing rate of change, uncertainty, and the complexity of multidirectional interdependencies between and within the social system and its environment. The third track emerged owing to the societal problems that were clearly outside in the domain of one single organization. And finally, the fourth track was developed, also intensely engaged with trying to improve the human condition, in highly conflictual settings, particularly ones that tend to produce protracted and apparently unresolvable disputes.

It is important to note, once again, that the development of the ETSP tracks are not sequential in the sense that the second started where the first track ended, and so on. On the contrary, for instance, the first track is very much vibrant today, where the technology is moving at an even faster rate than the social system's ability to adapt to the changes in technology. Furthermore, it should not be assumed that there is a hierarchy between the different tracks. There is no tendency to claim that the design and liberation issues confronted in any particular track are more or less pertinent compared to other tracks. Although the liberation issues in each track are different, they should be regarded as complimentary. To adopt a systems approach for liberating social systems, it becomes necessary to cover all the liberation issues in the design process, as the relevant contexts explicated in each track enter the discourse.

One of the final points to be made rests on the self-critical nature of the ETSP. Each track has exposed a new context and added a new perspective for a more complete appreciation of systemic nature of inquiry in purposeful systems. The addition of a new perspective and a new context can thus be interpreted as an expression of the critical nature of the paradigm development because each track taken alone will not address the systems idea comprehensively. What made critique easy stems from the fact that the paradigm development was not controlled solely by Fred Emery or Eric Trist, although they influenced many contributors, nor was it planned in a manner associated with the more formalistic approaches based on objective criteria. Rather, each developmental track emerged distinctively based on the nature of the contexts that were confronted and guided by the democratization objective and the systems approach. The paradigm development therefore followed a decentralized path, as action researchers working in similar or very different fields tried to make sense of the phenomenon and 
the design issues with which they were confronted. Contributions to the paradigm were diffused very quickly to action researchers in what might be described as a loosely coupled network covering different parts of the world.

The ETSP has proven to be open ended and will remain so. To anticipate the fifth and sixth tracks is as contrary to the ETSP developmental tracks as what I have done in this paper with some discomfort, that is, to expose the rational justifications for each track. However, it is self-evident that the securing of democractic and pluralistic principles in the redesign of oppressive institutions, organizations, and societies presents significant challenges. Suffice it to state that the fifth and the sixth tracks await to carry the liberationist theme into new contexts.

\section{REFERENCES}

Ackoff, R. L., and Emery, F. (1972). On Purposeful System, Aldine, Chicago.

Babürogilu, O. N. (1988). The vortical environment: The fifth in the Emery-Trist levels of organizational environments. Hum. Relat. 41(3), 181-210.

Babüroǵlu, O. N. (1991). Is the end of free fall, free fall? Surrendering as the focus of adaptation in vortical environments. In Geyer, F. (ed.). The Cybemetics of Complex Systems-Self Organization, Evolution, and Social Change. Intersystems Publications, Seaside, California.

Bain, A. (1976). Presenting problems in social consultancy: Three case histories concerning the selection of managers. Hum. Relat. 29(7), 643-657.

Crombie, A. (1984). The nature and types of search conferences. Int. J. Lifelong Educ. 4(1), 3-33.

Cummings, T. G., and Srivastva, S. (1977). Management of Work: A Socio-technical Systems Approach, Kent State University Press, Kent, OH.

Emery, F. E. (1977). Futures We Are in, Martinus Nijhoff, Leiden.

Emery, F. E. (1982). New perspectives on the world of work: Sociotechnical foundations for a new social order. Hum. Relat. 35(12), 1095-1122.

Emery, F. E. (1989). The jury system and participative democracy. In Emery, M. (ed.), Participative Design for Participative Democracy, ANU, Canberra.

Emery, F. E. (1989). Educational paradigms: An epistemelogical revolution. In Emery, M. (ed.), Participative Design for Participative Democracy, ANU, Canberra.

Emery, F. E. (1989). The light on the hill-skill formation or democratization of work. In Emery, M. (ed.), Participative Design for Participative Democracy, ANU, Canberra.

Emery, F. E. (1989). Toward Real Democracy and Toward Real Democracy: Further Problems, Ontario Quality of Working Life Centre, Toronto.

Emery, F. E. (1977). Futures We Are in, Martinus Nijoff, Linden.

Emery, F. E., and Thorsrud, E. (1969). Form and Content in Industrial Democracy, Tavistock, London.

Emery, F. E. and Thorsrud, E. (1976). Democracy at Work, Martinus Nijhoff, Leiden.

Emery, F. E., and Trist, E. (1965). Causal texture of organizational environments. Hum. Relat. 18(1), 21-32.

Emery, F. E., and Trist, E. (1973). Towards A Social Ecology, Plenum, New York.

Emery, M. (1982). Searching, Centre for Continuing Education, ANU, Canberra.

Emery, M., and Emery, F. E. (1978). Searching: For new direction, in new ways-for new times, in Sutherland, J. W. (ed.), Management Handbook for Public Administrators, Van Nostrand Reinhold, New York. 
Flood, R. L. (1990). Liberating systems theory: Toward critical systems thinking. Hum. Relat. 43(1), 49-75.

Foucault, M. (1980). In Gordon, C. (ed.), Power/Knowledge: Selected Interviews and Other Writings 1972-1977, Pantheon, New York.

Jackson, M. C. (1988). Systems methods for organizational analysis and design. Syst. Res. 5(3), 201-210.

Jackson, M. C., and Keys, P. (1984). Toward a system of systems methodologies. J. Oper. Res. Soc. 35(6), 473-486.

Kuhn, T. S. (1970). The Structure of Scientific Revolutions, 2nd ed., University of Chicago Press, Chicago.

McCann, J. E., and Selsky, J. (1984). Hyperturbulence and the emergence of type 5 environments. Acad. Manage. Rev. 9, 460-471.

Miller, E. J., and Rice, A. K. (1967). Systems of Organization, Control of Task and Sentient Boundaries, Tavistock, London.

Morley, D. (1989). Frameworks for organizational change: Towards action leaming in global environments. In Wright, S., and Morley, S. (eds.), Learning Works: Searching for Organizational Futures, ABL Group, York University, Toronto.

Ramirez, R. (1989). The social architecture of l'association du Puy du Fou. In Wright, S., and Morley, D. (eds.), Learning Works: Searching for Organizational Futures, ABL Group, York University, Toronto.

Schecter, D. (1990). Critical systems thinking in the 1980s: A connective summary. In Flood, R. L., and Jackson, M. C. (eds.), Critical Systems Thinking: Directed Readings, John Wiley \& Sons, New York.

Schon, D. (1971). Beyond the Stable State, WW Norton, New York.

Trist, E. L. (1977). A concept of organizational ecology. Austral. J. Manage. 2, 162-175.

Trist, E. L. (1977). A concept of organizational ecology. Austral. J. Manage. 2, 162-175.

Trist, E. L. (1981). The evolution of socio-technical systems: A conceptual framework and an action research program. In Van de Ven, A., and Joyce, W. (eds.),. Perspectives on Organizational Design and Behavior, Wiley Interscience, New York.

Trist, E. L. (1983). Referent organizations and the development of inter-organizational domains. Hum. Relat. 36(3), 269-284.

Trist. E. L. (1985). After-dinner remarks. Conference on Explorations in Human Futures. Orilla, Ontario.

Trist, E. L., and Bamforth, K. W. (1951). Some social and psychological consequences of the longwall method of coal getting. Hum. Relat. 4, 3-38.

Trist, E. L., Higgin, G. W., Murray, H., and Pollock, A. B. (1963). Organizational Choice, Tavistock, London.

Ulrich, W. (1983). Critical Heuristics of Social Planning: A New Approach to Practical Philosophy, Haupt, Berne.

Ulrich, W. (1987). Critical heuristics of social systems design. Eur. J. Operat. Res. 31, 276-283.

Ulrich, W. (1988). Systems thinking, systems practice, and practical philosophy: A programme of research. Syst. Pract. 1(2), 137-163.

van Beinum, H. (1990). Observations on the development of a new organizational paradigm. Paper presented at the seminar on Industrial Democracy in Western Europe, Cologne.

Vickers, G. (1973). Foreward. In Emery, F. E., and Trist, E. (eds.), Towards A Social Ecology, Plenum, New York.

Wright, S., and Morley, D. (1989). Learning Works: Searching for Organizational Futures, ABL Group, York University, Toronto. 